\title{
Bulgarian funding agency accused of poor practice
}

\section{Former director claims his efforts to reform National Science Fund have been hindered.}

\section{BY ALISON ABBOTT}

S cience in Bulgaria, already hobbled by a cash shortage and by faltering reforms of communist-era institutions, is facing a new setback. Its main source of cash, the Bulgarian National Science Fund (NSF), has been accused of mismanagement - by its own former director, Emil Horozov. An investigation commissioned by Horozov found widespread irregularities in the NSF's handling of funding requests in 2008 and 2009 , including using unqualified referees, and selectively ignoring referees' comments to favour particular projects.

When a summary of the investigation's report was published online in March, four months after the report was delivered to the country's Ministry for Education, Youth and Science, angry Bulgarian scientists accused the minister, Sergei Ignatov, of suppressing the findings.

Ignatov, who became minister in 2009 , says that he had not suppressed the report, and had passed it to a committee of the finance ministry in December 2010 to review the claims of funding mismanagement. "Such serious allegations need professional analysis," he says. "I expect to receive a response in the very near future."

Horozov, a reputed mathematician at Sofia University, commissioned the investigation a few weeks after he became director of the NSF in January 2010. He had noted that many of the NSF's funding decisions seemed to be being made in a secretive way. So he appointed a working group of eight independent scientists to examine the refereeing and selection of the nearly 2,000 proposals competing for a share of 250 million leva (US\$181,000) over the previous two years. The committee delivered a detailed report in October 2010, which was passed to the ministry the following month.

The report claims that many of the 230 reviewers who were chosen to assess the proposals had no science degrees or academic position. "One professor of English reviewed a paper in biochemistry," says Horozov. Each of the reviewers was allowed to select which grant proposals he or she would review from

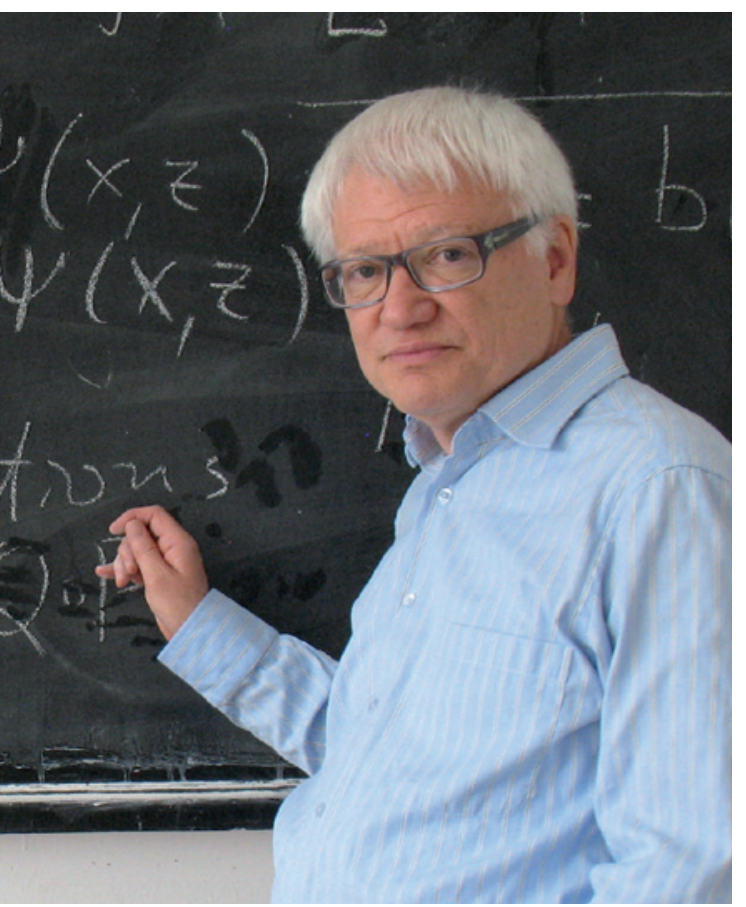

Emil Horozov has quit as head of Bulgaria's main funding agency.

the whole list, a practice that is unheard of in funding agencies. As the reviewers were paid for each review they produced, Horozov believes that this system may have been abused by some reviewers to boost their fees. "Several referees, even those without any form of scientific qualification, managed to comment on 100-200 applications within just two months."

\section{MISDIRECTION}

In 2009, about 200 projects were selected for funding. In 82 cases, however, the investigation found that one or more of the reviews had not been taken into account; had they been, all but three projects would have fallen below the funding threshold. Although not illegal, this is certainly bad practice, says Horozov. About 50 reviews relating to unfunded projects were found to have been withheld. All of them gave

\section{DNATURE.COM}

For more on

Bulgaria's science

crisis, see go.nature.

com/6icjlr. higher scores than the projects' averages - had they been included, 12 of the projects would have been raised above the funding threshold. "If the allocation of money had been made randomly, the results would have been fairer," says Horozov, adding that, "Bulgaria is a poor country. If the very small amount of research money it does have had been spent well, it could have done a lot of good."

The investigation also found that some of the referees reviewed competitors' applications, violating conflictof-interest rules. Furthermore, some thematically unrelated, low-scoring proposals were pooled to give a higher overall score, which was then used to justify giving full funding to each individual project. The report also claims that the NSF paid a company the highly inflated price of 186,000 leva for an online grantproposal submission system without putting out a tender, as the law requires.

After waiting for more than three months to get a response from the science ministry, Horozov resigned as NSF director on 23 February, saying that Ignatov had also hindered his efforts to prevent further corruption in the agency. Horozov says that when he became director, he understood that he would have the power to reform the NSF, modelling its structure on that used by successful European researchfunding agencies. He presented a proposal on this to the minister in October 2010 but says he got no response. Ignatov says he received no concrete proposal, but that his ministry had in any case been busy with many other reforms.

Two weeks ago, Horozov posted a summary of the investigation on his webpage (see go.nature.com/exqfy5) and described its contents in open lectures at the University of Sofia and the Bulgarian Academy of Sciences. On 24 March the Civil Movement for Support of Science and Education in Bulgaria, a grassroots organization of academics, issued a statement of support for Horozov, and called for Ignatov to resign.

Pavel Kerchev, a Bulgarian PhD student at the University of Leeds, UK, says that the scandal comes as no surprise. "Bulgaria is a small society and scientists have long been aware that the NSF was not working properly. It was just a matter of time before someone had the courage to bring it out publicly." - 